\title{
Ofensores sexuais avaliados pelo Desenho da Figura Humana
}

\author{
Juliane Magda Casarin ${ }^{1}$ \\ Université Paris VIII, França \\ Elizabeth Hertel Lenhardt Botelho \\ Universidade de Cuiabá, Cuiabá-MT, Brasil \\ Rosangela Kátia Sanches Mazzorana Ribeiro \\ Universidade Federal de Mato Grosso, Cuiabá-MT, Brasil
}

\section{RESUMO}

Este estudo se propôs a avaliar características psicológicas de ofensores sexuais intrafamiliares. Participaram do estudo 10 homens, entre 23 e 59 anos de idade, em situação de reclusão em um Centro de Ressocialização, pelo artigo 213 do Código Penal Brasileiro. Uma entrevista semidirigida e o Desenho da Figura Humana foram utilizadas como instrumentos. A coleta dos dados ocorreu de forma individual, sendo analisados no programa estatístico SPSS versão 22.0, para elaboração de análises descritivas simples. Os resultados dessa amostra apontam indicativos de dificuldade em lidar com impulsos corporais na busca pela satisfação imediata das necessidades, inclusive e, sobretudo, sexuais. Essas características foram recorrentes em alguns elementos dos desenhos, como a perspectiva em relação à localização na página, o tronco omitido e ausência de pupila nos olhos. Os principais resultados corroboram as características de personalidade retratadas comumente na literatura e confirmam a inexistência de um perfil psicológico para o ofensor sexual.

Palavras-chave: desenho de figura humana; personalidade; vitimização sexual da criança.

\section{ABSTRACT - Sex offenders evaluated using the Human Figure Drawing}

The aim of this study was to evaluate psychological characteristics of intra-family sexual offenders. The study included 10 men, between 23 and 59 years of age, who are inmates in a Resocialization Center as a function of Article 213 of the Brazilian Penal Code. A semi-structured interview and Human Figure Drawing were used, individually, as data collection instruments. Findings were analyzed by the statistic program SPSS version 22.0 for preparation of simple descriptive analyses. The results from this sample indicated difficulty in dealing with physical impulses in seeking immediate satisfaction of needs, including, and primarily, sexual needs. These characteristics were recurrent in some elements of the drawings, such as the location on the paper, the omission of the midsection and the absence of pupils in the eyes. The main findings corroborate the personality characteristics commonly portrayed in the literature and confirm the inexistence of a psychological profile of a sexual offender.

Keywords: human figure drawing; personality; child sexual victimization.

\section{RESUMEN - Delincuentes sexuales evaluados por el Dibujo de la Figura Humana}

Este estudio se propuso evaluar las características psicológicas de delincuentes que han cometido violencia sexual intrafamiliar. Participaron del estudio 10 hombres, entre 23 y 59 años de edad, en estado de reclusión en un centro de reinserción social, por el artículo 213 del Código Penal Brasileño. Se utilizaron como instrumentos una entrevista semi-dirigida y el dibujo de la figura humana. La recolección de los datos se realizó en forma individual y se analizaron los mismos mediante la programación estadística SPSS versión 22.0, para la elaboración de análisis descriptivos simples. Los resultados de esta muestra señalan indicativos de dificultad en lidiar con impulsos corporales, en la búsqueda de satisfacción inmediata de las necesidades, principalmente sexuales. Esas características fueron recurrentes en algunos elementos de los dibujos, como la perspectiva en relación a la ubicación en la página, el tronco omitido y ausencia de pupila en los ojos. Los principales resultados confirman las características de la personalidad comúnmente retratadas en la literatura y también la ausencia de un perfil psicológico para el delincuente sexual.

Palabras clave: dibujo de la figura humana; personalidad; victimización sexual del niño.

As práticas violentas de interação social, sendo elas domésticas ou não, têm um caráter histórico e estruturalmente relevante no Brasil. Tais práticas nasceram com a colonização do território, cresceram com o regime escravocrata e encontram-se presentes na sociedade até os dias atuais (Andrade, 2003). Trata-se de um fenômeno universal, que atinge todas as idades, níveis sociais e econômicos, etnias, religiões e culturas (Pfeiffer \& Salvagni, 2005). Dentre as diversas formas de violência contra crianças e adolescentes, o abuso sexual é uma das mais 
graves, recorrentes e geradora de efeitos negativos para o desenvolvimento emocional das vítimas.

A Organização Mundial de Saúde (OMS, 2002) define o abuso sexual infantil como o envolvimento de uma criança ou adolescente em atividade sexual que não compreende totalmente, que é incapaz de dar consentimento e para a qual a criança não está preparada por ainda estar em desenvolvimento, o que viola as leis ou tabus da sociedade. É evidenciada a violência doméstica sexual contra crianças e adolescentes em qualquer atividade entre uma criança menor de 18 anos (dependente) e um adulto (protetor) ou outra criança (Azevedo \& Guerra, 2007), que, pela idade ou estágio de desenvolvimento, está em uma relação de responsabilidade, confiança ou força, como irmãos e primos mais velhos, sendo que tal abuso é destinado à gratificação ou satisfação das necessidades dessa outra pessoa. Torna-se relevante salientar que a agressão sexual cometida pelo pai biológico é uma das mais frequentes (Azevedo \& Guerra, 2011). Embora não se limite a isso, essa prática pode incluir a indução ou coerção de uma criança para engajar-se em qualquer atividade sexual, a exploração de uma criança em sexo comercial ou outra prática sexual ilegal e o uso de crianças em performances ou materiais pornográficos.

Os abusadores sexuais de crianças têm sido tradicionalmente retratados ao público em geral como sujeitos psicologicamente doentes (geralmente psicóticos, psicopatas ou introvertidos), que atuam como predadores desenfreados de crianças. Tal estereótipo é provavelmente originado pela extensa cobertura midiática dos casos mais aberrantes e chocantes para a opinião pública (Fox, 2013; Mcalinden, 2014; Olver \& Barlow, 2010; Pechorro, Poiares, \& Vieira, 2008; Zgoba \& Levenson, 2012). Em contrapartida, a carência de estudos com essa população revela que a avaliação da psicodinâmica de homens sob reclusão é relevante. As pesquisas demonstram que não há um perfil psicológico desse agressor (Azevedo \& Guerra, 2011; Morrell \& Burton, 2014; Passetti, 1999; Riveira, Ramírez, Montoya, \& Quiroz, 2013). No entanto, alguns indicativos precisam ser melhor investigados. Dentre esses indicativos, encontram-se, por exemplo, a forma de estabelecimento e manutenção das relações socioafetivas (Azevedo \& Guerra, 2011; Lu \& Lung, 2012), a história pregressa dos sujeitos ofensores e características de personalidade que apontam a dificuldade em controlar os impulsos e os desejos (Chagnon, 2014; Glowacz \& Born, 2013; Pasqualini-Casado, Vagostello, Villemor-Amaral, \& Nascimento, 2008; Young, Justice, \& Edberg, 2010).

São diversos os instrumentos psicológicos que avaliam aspectos da personalidade. As técnicas projetivas são utilizadas com o objetivo de conhecer elementos sobre a personalidade da pessoa e de seu funcionamento egóico. Os testes gráficos desempenham importante papel na avaliação psicológica, pois detectam, com precisão, níveis profundos de integração e estruturação da personalidade
(Grassano, 1996). Esses testes, comparados a testes verbais, apresentam menos possibilidades de disfarces e controles intelectuais, portanto, são os que permitem determinar com maior precisão as características estruturais de integração da personalidade. A partir do uso dos métodos projetivos, pressupõe-se que se conheçam peculiaridades do sujeito, tanto nos aspectos estruturais quanto na psicodinâmica afetiva. Assim, as técnicas são capazes de expressar as modalidades de funcionamento psíquico próprias de cada sujeito, em suas especificidades e articulações singulares (Cardoso \& Capitão, 2006).

Estudos com autores de agressões sexuais em reclusão judiciária apontam a existência de diversas manifestações psíquicas que constituem vasto campo de fenômenos psicopatológicos e de personalidade (Balier, 1999). Dentre os traços de personalidade comumente verificados, encontram-se timidez, introversão, dificuldade de estabelecer laços sociais e baixa competência social (Costa \& Mello, 2012; Darves-Bornoz, 2001; Jumper, Babula, \& Casbon, 2012; Perrot, Bénoy, Chahraoui, \& Juif, 2014).

Na mesma direção, Scortegagna e Amparo (2013) afirmam que estudos com abusadores sexuais apontam heterogeneidade em suas características de personalidade. No entanto, segundo as autoras, certos transtornos de personalidade ou de sexualidade são comumente observados. Assim, alguns traços personalidade aparecem com mais frequência entre agressores sexuais, como dificuldades em controlar impulsos e em estabelecer relações interpessoais íntimas, autoestima rebaixada e hostilidade.

A pesquisa de Bridges, Wilson e Gacono (1998), que utilizou a técnica projetiva do Rorschach, apontou características comuns aos ofensores sexuais. Foram elas: baixa capacidade de estabelecer relações interpessoais, dependência infantil, vulnerabilidades narcísicas, representações imaturas do eu próprio e do outro, hostilidade e grande propensão a buscar objetos gratificantes em outras pessoas. Esses dados reafirmam resultados frequentemente retratados na literatura (Etcheverría, 2009; Chudzik \& Réveillère, 2013).

A partir de estudos com métodos projetivos na avaliação da personalidade de ofensores sexuais, Lafortune (2006) assinala que a análise do desenho de figura humana realizado por ofensores sexuais em reclusão exprime imaturidade sexual. Os trabalhos feitos por Miller (1995) e Matavitch (1998) propõem algumas características comuns aos desenhos de agressores sexuais, como olhos sem pupilas, nariz longo e pés grandes. Esses traços dos desenhos sugerem semelhanças no funcionamento psicodinâmico dos sujeitos. Contudo, os autores concordam que não há um grupo de características de personalidade próprias e únicas aos agressores sexuais.

No estudo de Azevedo e Guerra (2011), em que foram usadas duas técnicas projetivas (Procedimento de Desenhos-Estória com Tema e o questionário 
desiderativo), verificou-se que agressores sexuais domésticos, de forma geral, apresentam sinais de ego integrado, com poucos indicadores de transtornos de personalidade, porém fortes tendências à manifestação de impulsos narcisistas, diminuindo ou extinguindo a alteridade. Com a análise do Procedimento de DesenhosEstória com Tema, a criança foi representada de maneira adultificada (Azevedo \& Guerra, 2011), o que indica dificuldade em considerar a infância como uma fase de desenvolvimento e a criança como um sujeito merecedor de respeito e consideração.

Com base na necessidade de mais estudos sobre o tema, sobretudo na realidade nacional, o presente estudo teve como objetivo geral avaliar características da personalidade de ofensores sexuais sob pena de reclusão em um Centro de Ressocialização. Como objetivos específicos, primeiramente, buscou-se examinar a recorrência das características de personalidade desses sujeitos no desenho da figura humana, a fim verificar a existência de possíveis traços em comum. E, em segundo lugar, levantou-se a hipótese da existência, nos desenhos de figura humana de ofensores sexuais, de sinais sugestivos de dificuldade em lidar com impulsos corporais na busca pela satisfação imediata das necessidades. Para tanto, verificou-se a presença de indicadores dessas características de personalidade em seus desenhos de figura humana, como a perspectiva do desenho em relação à página, a omissão do tronco e a ausência de pupila nos olhos.

\section{Método}

\section{Participantes}

Nesta pesquisa, participaram 10 homens em situação de reclusão por estupro intrafamiliar, enquadrados no artigo 213 do Código Penal Brasileiro². Os casos foram selecionados por conveniência, de forma não aleatória, a partir da análise dos processos disponibilizados pela instituição penal onde estavam alocados, na cidade de Cuiabá/Mato Grosso. Em relação aos critérios de inclusão na amostra, foram considerados homens condenados (enquadrados no artigo 213) e que haviam cometido abuso sexual intrafamiliar, selecionados do conjunto de indivíduos reclusos nessa instituição penal.

\section{Instrumentos}

$\mathrm{Na}$ realização desta pesquisa, foram utilizados dois instrumentos, nomeadamente uma entrevista semidirigida (elaborada pelas pesquisadoras), usada com o propósito de levantar informações sociodemográficas, e o desenho da figura humana, analisado sob o referencial do manual técnico do teste HTP (Buck, 2003), bem como de referências complementares.

Para este estudo, foram solicitadas somente as figuras humanas (homem e mulher), visto que elas representam o autorretrato, o "eu". De acordo com Retondo (2000), o desenho da figura humana apresenta três tipos de projeções: a primeira faz referência ao autorrelato, o examinando desenha o que ele acredita ser; a segunda seria o eu ideal ou ideal de ego, o examinando desenha o que ele queria ser; e, por fim, há a percepção das pessoas significativas, em que o examinando desenha figuras importantes da sua vida, como os pais, professores e outros. No presente estudo, foram analisadas as seguintes variáveis relativas ao desenho da figura humana (Buck, 2003; Retondo, 2000): tempo para início da produção, rasuras, forma e força dos traçados, sexo da primeira figura desenhada, presença ou ausência de partes corporais consideradas secundárias. Também foram analisadas as características gráficas do desenho (Buck, 2003; Retondo, 2000), tais como a qualidade da linha, a localização do desenho na folha e a presença ou ausência de rasuras ou transparências.

\section{Procedimentos}

Este estudo teve seu projeto submetido ao Comitê de Ética e Pesquisa do Hospital Universitário Júlio Müller - HUJM e recebeu aprovação em 2012 sob o protocolo de número 170. A coleta de dados foi iniciada após a autorização dos participantes por meio do Termo de Consentimento Livre e Esclarecido (TCLE), seguindo as normas da pesquisa voluntária com seres humanos, que atende a resolução 466, de 2012, do Conselho Nacional de Saúde. A instituição forneceu um termo de autorização para que a pesquisa fosse realizada dentro do ambiente prisional. Em um só encontro com dois pesquisadores, foi feita, primeiramente, a entrevista semidirigida e, em seguida, a solicitação dos desenhos da figura humana. A coleta dos dados ocorreu de forma individual na unidade prisional, em uma sala disponibilizada pela instituição, com duração aproximada de 45 minutos, com média de 15 minutos para a entrevista semidirigida, 15 minutos para a elaboração dos desenhos de figura humana e outros 15 minutos para o questionário posterior sobre os desenhos.

\section{Análise de Dados}

Após a coleta de dados, eles foram sistematizados conforme Buck (2003) e Retondo (2000), tabulados em programa Microsoft Excel 2007 e analisados no programa estatístico SPSS versão 22.0. Foram feitas análises descritivas simples para as variáveis categóricas e, para as variáveis numéricas, foram calculados a média e desvio padrão dos dados. 


\section{Resultados}

A Tabela 1 demonstra os dados referentes às informações sociodemográficas dos sujeitos entrevistados. Os dados levantados foram: idade, escolaridade, estado civil, religião, profissão, número de filhos e uso de substâncias psicoativas.

Quanto à faixa etária, a amostra variou entre 23 e 60 anos, sendo que $50 \%(n=5)$ dos sujeitos encontram-se entre 36 e 48 anos, com média de 41,4 anos e desvio padrão de 10,9 anos. No que se refere à escolaridade, a maior porcentagem observada no ensino fundamental completo/incompleto $(50 \%, n=5)$. Quanto à religião, todos os sujeitos $(100 \%, N=10)$ responderam que seguiam a religião evangélica dentro da instituição, sendo que, destes, três disseram que seguiam outras religiões (católica e espírita) "lá fora", isto é, antes de estarem reclusos.

Tabela 1

Dados Sociodemográficos dos Reeducandos do Centro de Ressocialização de Cuiabá/MT

\begin{tabular}{|c|c|c|}
\hline Variáveis & $f$ & $\%$ \\
\hline \multicolumn{3}{|l|}{ Idade } \\
\hline 23 a 35 anos & 3 & 30 \\
\hline 36 a 48 anos & 5 & 50 \\
\hline 49 a 60 anos & 2 & 20 \\
\hline \multicolumn{3}{|l|}{ Escolaridade } \\
\hline Ensino fundamental completo/incompleto & 5 & 50 \\
\hline Ensino médio completo/incompleto & 3 & 30 \\
\hline Ensino superior completo/incompleto & 2 & 20 \\
\hline \multicolumn{3}{|l|}{ Estado civil } \\
\hline Com companheira & 7 & 70 \\
\hline Sem companheira & 3 & 30 \\
\hline \multicolumn{3}{|l|}{ Religião } \\
\hline Com religião & 10 & 100 \\
\hline Sem religião & - & - \\
\hline \multicolumn{3}{|l|}{ Profissão } \\
\hline Setor primário & 1 & 10 \\
\hline Setor secundário & 3 & 30 \\
\hline Setor terciário & 6 & 60 \\
\hline \multicolumn{3}{|l|}{ Número de filhos } \\
\hline Nenhum & 2 & 20 \\
\hline Um ou dois & 2 & 20 \\
\hline Três ou mais & 6 & 60 \\
\hline \multicolumn{3}{|l|}{ Psicoativos } \\
\hline Nunca usou & 4 & 40 \\
\hline Apenas drogas lícitas & 4 & 40 \\
\hline Drogas ilícitas & 2 & 20 \\
\hline
\end{tabular}

Em relação à profissão, a apresentação dos resultados seguiu a equivalência dos setores da economia (primário, secundário e terciário). São atividades do setor primário a agricultura, mineração, pesca, pecuária extrativismo vegetal e caça. O setor secundário é responsável por transformar as matérias-primas (setor primário) em produtos industrializados. E o setor terciário é relacionado à prestação de serviços. Neste estudo, considerando essa subdivisão, mais da metade dos sujeitos $(60 \%, n=6)$ exerciam atividades no setor terciário. O setor secundário compreendeu três sujeitos $(30 \%)$. Por fim, no setor primário atuava apenas um indivíduo (10\% da amostra).

Em relação ao número de filhos, $60 \%(n=6)$ verbalizaram ter três ou mais filhos. Quanto ao uso de substâncias psicoativas, $40 \%(n=4)$ referiram que nunca as usaram. Essa mesma frequência foi identificada entre os que disseram fazer uso de drogas lícitas, $40 \%(n=4)$, 
sendo elas o álcool e o tabaco. Já em relação ao uso de drogas ilícitas, $20 \%(n=2)$ afirmaram o consumo de cocaína, maconha, pasta base e crack.

Os resultados referentes ao desenho da figura humana serão apresentados conforme as indicações de Buck (2003) e Retondo (2000). De acordo com Buck
(2003), indicadores relevantes do desenho da figura humana incluem: tempo para o início da produção, rasuras que foram feitas, forma e força das linhas, sexo da primeira figura desenhada, presença ou ausência de partes consideradas secundárias. Os achados vinculados a esses indicadores são apresentados na Tabela 2 .

Tabela 2

Itens Avaliativos do Desenho da Figura Humana de acordo com Buck (2003)

\begin{tabular}{|c|c|c|}
\hline Características & $f$ & $\%$ \\
\hline \multicolumn{3}{|l|}{ Tempo de latência } \\
\hline $\operatorname{Sim}$ & 10 & 100 \\
\hline Não & - & - \\
\hline \multicolumn{3}{|l|}{ Poucas rasuras } \\
\hline Sim & 8 & 80 \\
\hline Não & 2 & 20 \\
\hline \multicolumn{3}{|l|}{ Simetria } \\
\hline $\operatorname{Sim}$ & - & - \\
\hline Não & 10 & 100 \\
\hline \multicolumn{3}{|l|}{ Linhas não esboçadas ou reforçadas } \\
\hline Esboçada & 4 & 40 \\
\hline Não esboçada & 2 & 20 \\
\hline Reforçada & 1 & 10 \\
\hline Esboçada e reforçada & 1 & 10 \\
\hline Normal & 2 & 20 \\
\hline \multicolumn{3}{|l|}{ Próprio sexo desenhado primeiro } \\
\hline Sim & 6 & 60 \\
\hline Não & 4 & 40 \\
\hline \multicolumn{3}{|l|}{ Mais elaborado } \\
\hline Sim & 4 & 40 \\
\hline Não & 2 & 20 \\
\hline \multicolumn{3}{|l|}{ Características sexuais secundárias incluídas } \\
\hline Sim & 3 & 30 \\
\hline Não & 7 & 70 \\
\hline \multicolumn{3}{|l|}{ Pupilas desenhadas } \\
\hline Sim & 3 & 30 \\
\hline Não & 7 & 70 \\
\hline \multicolumn{3}{|l|}{ Nariz sem narinas } \\
\hline Sim & 5 & 50 \\
\hline Não & 5 & 50 \\
\hline \multicolumn{3}{|l|}{ Roupas e cintos indicados } \\
\hline Sim & 3 & 30 \\
\hline Não & 7 & 70 \\
\hline \multicolumn{3}{|l|}{ Pés } \\
\hline Sim & 7 & 70 \\
\hline Não & 3 & 30 \\
\hline \multicolumn{3}{|l|}{ Orelhas } \\
\hline Sim & 4 & 40 \\
\hline Não & 6 & 60 \\
\hline \multicolumn{3}{|l|}{ Apenas omissões secundárias } \\
\hline Sim & 5 & 50 \\
\hline Não & 5 & 50 \\
\hline
\end{tabular}


A Tabela 2 demonstra que 100\% $(N=10)$ dos sujeitos fizeram o desenho da pessoa dentro do tempo considerado normal para a faixa etária (de 10 a 12 minutos) e latência menor que 30 segundos para o início do desenho. O tempo utilizado para a realização da atividade pode fornecer indicativos acerca dos significados dos objetos desenhados e das suas representações para o indivíduo. Ou seja, ao desenhar a figura humana, o sujeito pode projetar características de sua relação consigo e com o sexo oposto. No que concerne ao primeiro desenho, ou seja, o desenho do próprio sujeito, pode-se supor que haja alguma valorização do "eu", no sentido de apresentar características relacionadas ao narcisismo. $\mathrm{Na}$ amostra do presente estudo, todos os sujeitos encontram-se dentro do esperado quanto ao tempo de latência do desenho (<30 segundos) para a faixa etária estudada.

Oito sujeitos (80\%) apresentaram poucas rasuras em seus desenhos, o que sugere positiva resposta no sentido de executar a atividade solicitada. Nenhum dos sujeitos apresentou simetria entre as partes do corpo no desenho, que pode indicar confusão no papel sexual e desequilíbrio de personalidade (Buck, 2003; Retondo, $2000)$. Sete sujeitos $(70 \%)$ omitiram a pupila, e essa omissão indica dificuldade de contato com a realidade ou recusa em enxergá-la. Já $50 \%$ dos sujeitos omitiram detalhes essenciais, como tronco e pernas, que sugerem conflitos com as partes omitidas e dificuldade em lidar com os impulsos presentes no corpo, implicando negação dos impulsos corporais.

Alguns detalhes essenciais do desenho, segundo sistema avaliativo de Buck (2003), são apresentados na Tabela 3. Esta aponta dados referentes a: proporção do desenho (item que avalia a relação entre o tamanho do desenho e a folha) e detalhes da figura (frequentemente revelam o valor atribuído pelo sujeito àquilo que é projetado no desenho).

Tabela 3

Itens Avaliativos Relativos à Proporção do Desenho da Figura Humana (Buck, 2003)

\begin{tabular}{lll}
\hline \multicolumn{1}{c}{ Proporção } & $f$ & $\%$ \\
\hline Tamanho da figura em relação à página & 6 & 60 \\
Pequeno & 2 & 20 \\
Grande & 2 & 20 \\
Normal & & 9 \\
Detalhe para a figura & 9 \\
$\quad$ Distorções óbvias & 1 & 10 \\
Distorções moderadas & \\
\hline
\end{tabular}

A Tabela 3 mostra que $60 \%(n=6)$ dos avaliados fizeram o desenho da pessoa de tamanho pequeno, algo que indica sentimento de inadequação, tendência em se afastar do ambiente ou rejeição do tema principal do desenho que, nesse caso, é o próprio "eu". Em relação às distorções, $90 \%(n=9)$ apresentaram distorções óbvias, ou seja, detalhes de tamanho menor do que a média, o que implica em rejeição ou em desejo de rejeitar o que o item pode simbolizar para o sujeito. $\mathrm{Na}$ amostra, houve distorção do tamanho dos olhos, do nariz e da boca, considerados detalhes essenciais de acordo com a análise de Buck (2003). Os olhos simbolizam o contato com o mundo exterior, e o desenho feito em proporção menor à média sugere dificuldade ou recusa da realidade. O nariz simboliza as simpatias, as antipatias e também a sexualidade. $\mathrm{Na}$ amostra avaliada, $30 \%(n=3)$ dos indivíduos fizeram o nariz enfatizado, o que sugere conflito interpessoal e/ou sexual. Já a boca simboliza a nutrição, a comunicação, a afetividade e a agressão. Nessa amostra, houve ênfase da boca, que pode indicar dificuldades de relacionamento interpessoal e também agressividade.
A perspectiva do desenho pode ser vista como sinal da compreensão do sujeito sobre seu modo de ver a vida, além de indicar a capacidade de compreender e reagir com sucesso aos aspectos mais complexos e exigentes da vida. Fazem parte das características de análise da perspectiva dos desenhos, segundo Buck (2003): localização na página, referente à posição dada na folha ao objeto desenhado; margens do papel, se foram feitas ou não; relação com o observador, ou seja, como o desenho é visto por quem segura a folha; presença ou ausência da linha do solo; presença ou não das transparências nos desenhos; presença ou não de rotação sugerida ou movimento do desenho. Essas características são apresentadas na Tabela 4.

Em relação à localização, $50 \%(n=5)$ dos indivíduos desenharam no quadrante superior à esquerda da folha, indicando regressão. Entretanto, quanto mais para a esquerda estiver o ponto médio da figura em relação ao ponto médio da folha, maiores são as probabilidades de o sujeito se comportar de forma impulsiva, buscando satisfação emocional direta e imediata de suas necessidades e impulsos (Buck, 2003), o que foi evidenciado nessa 
amostra. Nove sujeitos (90\%) não desenharam a margem do desenho, que sugere baixo contato com a realidade ou dificuldade em manter contato com ela. Os desenhos foram, geralmente, representados como se estivessem no mesmo nível do observador, e a distância, sugerida usualmente pelo tamanho pequeno do desenho, que denota forte necessidade de manter o self afastado e inacessível. Oito sujeitos (80\%) não apresentaram transparências em seus desenhos, sugestivo de preservação da função crítica, já que a transparência aponta para grave falha no teste de realidade.

Outros detalhes essenciais da figura humana de acordo com Buck (2003) são: cabeça, tronco, braços, pernas e traços faciais, que indicam o modo como o sujeito se relaciona com o mundo. A Tabela 5 sistematiza os dados obtidos com relação a essas características dos desenhos.

Tabela 4

Itens Avaliativos Relativos à Perspectiva do Desenho da Figura Humana (Buck, 2003)

\begin{tabular}{|c|c|c|}
\hline Perspectiva & $f$ & $\%$ \\
\hline \multicolumn{3}{|l|}{ Localização do desenho na página } \\
\hline À esquerda & 1 & 10 \\
\hline À direita & 1 & 10 \\
\hline Superior & 2 & 20 \\
\hline Superior à esquerda & 5 & 50 \\
\hline Normal & 1 & 10 \\
\hline \multicolumn{3}{|l|}{ Margens do papel } \\
\hline Não & 9 & 90 \\
\hline Margem impedindo desenho completo & 1 & 10 \\
\hline \multicolumn{3}{|l|}{ Relação com o observador } \\
\hline Distância & 6 & 60 \\
\hline Mistura de perfil e frente & 3 & 30 \\
\hline Normal & 1 & 10 \\
\hline \multicolumn{3}{|l|}{ Linha do solo } \\
\hline $\operatorname{sim}$ & 1 & 10 \\
\hline Não & 9 & 90 \\
\hline \multicolumn{3}{|l|}{ Transparências } \\
\hline Sim & 2 & 20 \\
\hline Não & 8 & 80 \\
\hline \multicolumn{3}{|l|}{ Rotação ou queda sugerida } \\
\hline $\operatorname{Sim}$ & - & - \\
\hline Não & 10 & 100 \\
\hline \multicolumn{3}{|l|}{ Movimento } \\
\hline Sim & - & - \\
\hline Não & 10 & 100 \\
\hline
\end{tabular}

Tabela 5

Itens Avaliativos Relativos a Detalhes do Desenho da Figura Humana (Buck, 2003)

\begin{tabular}{lll}
\hline \multicolumn{1}{c}{ Detalhes do desenho } & $f$ & $\%$ \\
\hline Cabeça, tronco, braços, pernas e traços faciais (presentes) & 5 & 50 \\
$\quad$ Sim & 5 & 50 \\
Não & & \\
Braços & 1 & 10 \\
Ênfase & 3 & 30 \\
Muito finos & 3 & 30 \\
Omitidos, muito pequenos, ocultos & 3 \\
\hline
\end{tabular}


Tabela 5 (continuação)

Itens Avaliativos Relativos a Detalhes do Desenho da Figura Humana (Buck, 2003)

\begin{tabular}{|c|c|c|}
\hline Detalhes do desenho & $f$ & $\%$ \\
\hline Em forma de asas & 1 & 10 \\
\hline Normais & 2 & 20 \\
\hline \multicolumn{3}{|l|}{ Cabeça } \\
\hline Grande & 7 & 70 \\
\hline Irregular ou não ligada & 3 & 30 \\
\hline \multicolumn{3}{|l|}{ Traços faciais } \\
\hline Perfil & 1 & 10 \\
\hline De animal ou bizarros & 6 & 60 \\
\hline Normais & 3 & 30 \\
\hline \multicolumn{3}{|l|}{ Olhos } \\
\hline Ênfase & 2 & 20 \\
\hline Pequenos, fechados, omitidos & 1 & 10 \\
\hline Pupilas omitidas & 6 & 60 \\
\hline Normais & 1 & 10 \\
\hline \multicolumn{3}{|l|}{ Orelhas } \\
\hline Ênfase excessiva & 2 & 20 \\
\hline Sem orelhas & 3 & 30 \\
\hline Normais & 5 & 50 \\
\hline \multicolumn{3}{|l|}{ Boca } \\
\hline Ênfase & 5 & 50 \\
\hline Ênfase e com dentes & 1 & 10 \\
\hline Normal & 4 & 40 \\
\hline \multicolumn{3}{|l|}{ Nariz } \\
\hline Ênfase & 3 & 30 \\
\hline Normal & 7 & 70 \\
\hline \multicolumn{3}{|l|}{ Gênero oposto desenhado primeiro } \\
\hline Sim & 4 & 40 \\
\hline Não & 6 & 60 \\
\hline \multicolumn{3}{|l|}{ Pernas } \\
\hline Omitidas, diminuídas, cortadas & 3 & 30 \\
\hline Posição afastadas & 2 & 20 \\
\hline Afastadas e diminuídas & 4 & 40 \\
\hline Afastadas e instável & 1 & 10 \\
\hline \multicolumn{3}{|l|}{ Omissões (conflito relativo à parte omitida) } \\
\hline Sim & 6 & 60 \\
\hline Não & 4 & 40 \\
\hline \multicolumn{3}{|l|}{ Tronco } \\
\hline Aberto & 1 & 10 \\
\hline Fragmentado & 1 & 10 \\
\hline Omitido & 4 & 40 \\
\hline Normal & 4 & 40 \\
\hline \multicolumn{3}{|l|}{ Seios } \\
\hline Sim & 1 & 10 \\
\hline Não & 9 & 90 \\
\hline \multicolumn{3}{|l|}{ Linha mediana vertical } \\
\hline Sim & - & - \\
\hline Não & 10 & 10 \\
\hline
\end{tabular}


Tabela 5 (continuação)

Itens Avaliativos Relativos a Detalhes do Desenho da Figura Humana (Buck, 2003)

\begin{tabular}{lll}
\hline \multicolumn{1}{c}{ Detalhes do desenho } & $f$ & $\%$ \\
\hline Ombros & 6 & 60 \\
Omitidos & 1 & 10 \\
Quadrados ou enfatizados & 3 & 30 \\
Normais & 3 & 30 \\
Linha da cintura enfatizada & 7 & 70 \\
Sim & 30 \\
Não & 1 & 10 \\
Linha da cintura apertada & 9 \\
Sim & 90 & 90 \\
\hline
\end{tabular}

No desenho da figura humana, o tronco representa necessidades e impulsos físicos básicos (Buck, 2003). Nessa amostra $50 \%(n=5)$, dos sujeitos desenharam apenas a cabeça (sem o tronco), o que sugere dificuldade em lidar com os impulsos presentes no corpo, implicando negação dos impulsos corporais. A distorção ou omissão de qualquer parte da figura pode sinalizar conflitos, sendo comum a expressão de conflitos sexuais por meio da omissão de partes do corpo, como, por exemplo: membros inferiores. Mais especificamente, voyeuristas tendem a omitir os olhos, pessoas com alto nível de insegurança tendem a omitir os braços, já que estes simbolizam força, doação, agressividade e interação com o mundo. $\mathrm{O}$ desenho apenas da cabeça implica censura ao próprio corpo ou sexual e, em alguns casos, pode indicar refúgio na fantasia (Retondo, 2000). Os braços são vistos como instrumentos de controle ou para realizar mudanças no ambiente e sua omissão sugere forte sentimento de inadequação. Sobre os braços, apenas $20 \%(n=2)$ fizeram o desenho considerado normal, o restante apresentou irregularidade. A ausência das pernas sugere fortes sentimentos de constrição e, provavelmente, preocupações igualmente fortes de castração, aparecendo em $50 \%(n=5)$ da amostra. Quanto à análise dos olhos, $60 \%(n=6)$ dos avaliados desenharam buracos "ocos", sem nenhuma tentativa de delinear a íris ou a pupila, o que indica contato pobre com a realidade (Buck, 2003). A boca, órgão em que se presume ser receptor dos prazeres mais precoce, pode ser também instrumento de agressão, e em 50\% $(n=5)$ dos indivíduos desse estudo foi enfatizada, sugerindo sinais de erotismo oral e/ou tendências orais agressivas.

A qualidade da linha presente nos desenhos pode apresentar algumas características da personalidade (Buck, 2003). A Tabela 6 apresenta os dados referentes à análise desse quesito avaliativo.

Tabela 6

Itens Avaliativos Relativos à Qualidade da Linha do Desenho da Figura Humana (Buck, 2003)

\begin{tabular}{|c|c|c|}
\hline Qualidade da linha & $F$ & $\%$ \\
\hline Fragmentação & 2 & 20 \\
\hline Dificuldade em ângulos & 2 & 10 \\
\hline Forte e fragmentação & 2 & 20 \\
\hline Forte, fragmentação e dificuldade em ângulos & 1 & 10 \\
\hline Fragmentação e dificuldade em ângulos & 2 & 20 \\
\hline Normal & 1 & 10 \\
\hline
\end{tabular}

A Tabela 6 mostra que $90 \%(n=9)$ dos sujeitos apresentaram algum comprometimento na qualidade da linha (fragmentação e ângulos em $50 \%$ dos casos, $n=5$ ), e/ou linha forte ( $30 \%$ dos avaliados, $n=3)$, indicando sinais de desajustamento funcional da personalidade. Os traçados fortes formaram o contorno da maior parte do desenho, enquanto outras linhas não tão fortes sinalizam esforços da pessoa para manter a integridade do ego. A ênfase nas linhas periféricas da cabeça sugere fortes esforços para manter o controle frente a fantasias perturbadoras, característica presente em $30 \%(n=3)$ dos desenhos. As linhas que são interrompidas e nunca se unem $(70 \%$, $n=7$ ) indicam indecisão e falha incipiente do funcionamento do ego. 
Em suma, verificou-se a recorrência de traços em comum nos desenhos, tais como: localização no quadrante superior esquerdo da página, ausência de simetria entre as partes do corpo, omissão do tronco, ausência de pupila, ausência da margem inferior e dificuldades com a qualidade da linha. Essas características confirmam a hipótese de que a análise do desenho da figura humana possibilitaria averiguar características de personalidade que indicam dificuldade em lidar com os impulsos narcisistas, conflitos com o corpo, dificuldade com a realidade e busca de satisfação imediata dos impulsos.

\section{Discussão}

Para o presente estudo, foram levantadas características sociodemográficas e de personalidade dos indivíduos a partir da análise do desenho da figura humana (Buck, 2003; Retondo, 2000). No que concerne aos dados sociodemográficos, verificou-se que a maioria possuía apenas o ensino fundamental $(50 \%$ dos casos com baixo nível de escolaridade). Esse dado deve ser interpretado de maneira cautelosa, visto que pessoas com melhor nível de escolaridade também cometem os mesmos atos (Dresdner et al., 2010). Não se pode considerar a violência sexual contra crianças e adolescentes um fenômeno da classe econômica baixa, análise esta corroborada no estudo de Azevedo e Guerra (2011). Além disso, Azevedo e Guerra (2010), Pinto Junior (2005) e Silva e Vecina (2002) relevam que a maioria das notificações referentes aos abusos sexuais, de fato, é proveniente de famílias de classes sociais D e E, de acordo com o critério estabelecido por Jannuzi e Baeninger (2008). No entanto, torna-se importante considerar que a revelação da violência sexual em classes sociais mais privilegiadas é menos evidente, pois fica envolta num pacto de silêncio que dificulta a denúncia (Azevedo \& Guerra, 2011; Fabián, Rojas, Gushiken, \& Gozzer, 2012).

A análise dos dados converge com as comumente apresentadas na literatura sobre a não existência de um perfil homogêneo e/ou características sociais, econômicas e de personalidade dos ofensores sexuais (Azevedo \& Guerra, 2011; Chagnon, 2011; Chagnon, 2014; Morrell \& Burton, 2014; Passetti, 1999; Riveira et al., 2013; Scortegagna \& Amparo, 2013). Entretanto, algumas características de personalidade foram mais frequentes neste estudo e demandam algumas considerações. Houve, nesses homens, indicativo de terem mais dificuldade em lidar com impulsos corporais na busca pela satisfação imediata de suas necessidades, sobretudo de natureza sexual. Essas características foram recorrentes em alguns elementos dos desenhos, como a perspectiva em relação à localização na página, o tronco omitido, ausência da pupila nos olhos. Elas, em conjunto, sugerem que esses sujeitos têm mais dificuldades em controlar seus impulsos físicos básicos e buscam satisfação imediata de suas necessidades, o que levanta a hipótese de que essas características podem ter influenciado no cometimento dos delitos sexuais, porém não se pode afirmar que elas estão presentes somente em abusadores sexuais.

De acordo com Scortegagna e Amparo (2013), a avaliação dos aspectos de personalidade com ofensores sexuais é um desafio na realidade brasileira, pois há escassez de trabalhos e de instrumentos de avaliação. Embora a literatura internacional aponte para a heterogeneidade das características de personalidade e psicopatológicas dos abusadores sexuais, houve evidência de algumas particularidades psicodinâmicas, tais como dificuldades em controlar os impulsos e em estabelecer relações de intimidade, personalidade imatura e instável, agressividade frente às frustrações, hostilidade e autoestima rebaixada.

O uso do método projetivo do desenho da figura humana permitiu examinar sinais do processo de adaptação à realidade dessas pessoas, colocando em evidência a fragilidade de suas disposições psicológicas e fornecendo dados singulares de cada sujeito. O estudo proporcionou algumas conclusões a seguir descritas. Houve semelhanças entre as variáveis sociodemográficas, tais como a idade dos ofensores (50\%, $n=5$, entre 36 e 48 anos), o nível de escolaridade ( $50 \%, n=5$, com ensino fundamental), o setor de trabalho $(60 \%, n=6$, no setor terciário) e a quantidade de filhos $(60 \%, n=6$, com três ou mais). Entretanto, não se pode afirmar que sujeitos com características sociodemográficas diferentes das encontradas, nessa amostra, não poderiam ser ofensores sexuais.

A partir do presente trabalho, não há como afirmar que as características dos desenhos se aplicam apenas aos homens agressores sexuais, pois o estudo foi realizado com reduzido número de participantes e não houve grupos comparativos. No entanto, a relevância deste trabalho é verificada ao encontrar dados que corroboram evidências retratadas pela literatura da área. No entanto, fazem-se necessários mais estudos acerca do fenômeno estudado, com grupos maiores e com outros métodos projetivos, como sugerido por outros investigadores da área (Achá, Rigonatti, Saffi, Barros, \& Serafim, 2011; Beech, Bartels, \& Dixon, 2013; Davis \& Archer, 2010; Levenson, Prescott, \& Jumper, 2014; Willians \& Finkelhor, 1990).

\section{Referências}

Achá, M. F. F., Rigonatti, S. P., Saffi, F., Barros, D. M., \& Serafim, A. P. (2011). Prevalence of mental disorders among sexual offenders and non-sexual offenders. Jornal Brasileiro de Psiquiatria, 60(1), 11-15. doi: 10.1590/S0047-20852011000100003 
Andrade, A. P. (2003). Violência doméstica contra crianças e adolescentes. Prevenção, repressão e proteção à vítima no âmbito brasileiro e latino-americano. Revista de Informação Legislativa, 40(160), 147-162. Recuperado de http:/www.senado.gov.br/web/cegraf/ril/Pdf/ pdf_160/RIL160-12.pdf

Azevedo, M. A., \& Guerra, V. N. A. (Eds.). (2007). Crianças vitimizadas: a síndrome do pequeno poder. São Paulo, SP: Iglu.

Azevedo, M. A., \& Guerra, V. N. A. (2010). Mania de bater: a punição corporal doméstica de crianças e adolescentes no Brasil (2a edição). São Paulo, SP: Iglu.

Azevedo, M. A., \& Guerra, V. N. A. (2011). Violência doméstica na infância e adolescência: uma nova cultura de prevenção. São Paulo, SP: Pleiade.

Balier, C. (1999). Psychanalyse des comportements sexuels violents. une pathologie de l'inachèvement. Paris, France: Presses Universitaires de France.

Beech, A. R., Bartels, R. M., \& Dixon, L. (2013). Assessment and treatment of distorted schemas in sexual offenders. Trauma, Violence E Abuse, 14(1), 54-66.

Bridges, M. R., Wilson, J. S., \& Gacono, C. B. (1998). A Rorschach investigation of defensiveness, self-perception, interpersonal relations and affective states in incarcerated pedophiles. Journal of Personality Assessment, 70(2), 365-385.

Buck, J. N. (2003). Casa-Árvore-Pessoa - HTP - Técnica projetiva de desenho: manual e guia de interpretação. (R. C. Tardivo, Trad.). São Paulo, SP: Vetor. (Original publicado em 1970).

Cardoso, L. M., \& Capitão, C. G. (2006). Estudo correlacional entre o teste de Pfister e o Desenho da Figura Humana. Revista Psico-USF, 11(2), 157-166. Recuperado de http://www.scielo.br/scielo.php?script=sci_arttext\&pid=S1413-82712006000200004

Chagnon, J. Y. (2011). Identification à l'agresseur et identification projective à l'adolescence. À propos d'un cas. L'Esprit du Temps, 115(2), $127-140$.

Chagnon, J. Y. (2014). Agressions sexuelles et dépendances à l'adolescence. Ágora: Estudos em teorias psicanalíticas, 17(spe), 85-98.

Chudzik, L., \& Réveillère, C. (2013). Déni complet des faits: une perspective interpersonnelle. Annales Médico-Psychologiques, 37(2), 257-276.

Código Penal Brasileiro. (1940). Artigo 213. Lei n 12.015 de 2009. Recuperado de http://www.planalto.gov.br/ccivil_03/decreto-lei/ del2848.html

Costa, C. S., \& Mello, M. F. (2012). Indicadores comportamentais de propensão ao homicídio em agressores sexuais. Jornal Brasileiro de Psiquiatria, 60(1), 33-38. doi: 10.1590/S0047-2085201200100007

Darves-Bornoz, J.-M. (2001). Existe-t-il des caractéristiques cliniques et psychopathologiques des adultes auteurs d'agressions sexuelles intra-familiales? Em Féderation Française de Psychiatrie (Eds.), Psychopatologie et traitement actuels des auteurs d'agression sexuelle (pp. 275-303). Paris, França: John Libbey Eurotext.

Davis, K. M., \& Archer, R. P. (2010). A critical review of objective personality inventories with sex offenders. Journal of Clinical Psychology, 66(12), 1254-1280.

Dresdner, C., Rodrigo, A., Guitiérrez, O., Arch, M., Peredta, N., Jarne, A... Sepulveda, M. (2010). Percepción parental temprana y experiencias del desarrollo en violadores. Revista Chilena de Neuro-Psiquiatría, 48(2), 96-105.

Etcheverría, P. J. (2009). Caracterización psicológica de un grupo de delincuentes sexuales chilenos a través del test de Rorschach. Psykhe, 18(1), 27-38. doi: 10.4067/S0718-22282009000100003

Fabián, F., Rojas, R., Gushiken, A., \& Gozzer, E. (2012). ¿Quién es la víctima y quién el agresor en la violencia física entre parejas? Estudio epidemiológico en siete ciudades del Perú. Revista Peruana de Medicina Experimental y Salud Publica, 29(1), 44-52.

Fox, K. (2013). Incurable sex offenders, lousy judges \& the media: Moral panic sustenance in the age of new media. American Journal of Criminal Justice, 38(1), 160-181.

Glowacz, F., \& Born, M. (2013). Do adolescents child abusers, peer abusers, and non-sex offenders have different personality profiles? European Child \& Adolescent Psychiatry, 22(2), $117-125$.

Grassano, E. (1996). Indicadores psicopatológicos nas técnicas projetivas. Jornal de Pediatria, 81(5), 197-204.

Jannuzzi, P. M., \& Baeninger, R. (2008). Qualificação socioeconômica e demográfica das classes da escala Abipeme. Revista de Administração, 31(3), 82-90.

Jumper, S., Babula, M., \& Casbon, T. (2012). Diagnostic profiles of civilly committed sexual offenders in Illinois and other reporting jurisdictions. International Journal of Offender Therapy and Comparative Criminology, 56(6), 838-855.

Lafortune, D. (2006). La délinquance sexuelle à la lumière des épreuves projectives. Em T. Pham (Ed.), Lévaluation diagnostique des agresseurs sexuels (pp.69-110) Paris, França: Mardaga.

Levenson, J. S., Prescott, D. S., \& Jumper, S. (2014). A consumer satisfaction survey of civilly committed sex offenders in Illinois. International Journal of Offender Therapy and Comparative Criminology, 58(2), 474-495.

Lu, Y.-C., \& Lung, F.-W. (2012). Perceived parental attachment, personality characteristics, and cognition in male incest. International Journal of Offender Therapy and Comparative Criminology, 56(4), 557-572.

Matavitch, M. A. (1998). Discriminant validity of the draw-a-person screening procedure for emotional disturbance for incarcerated juvenil delinquents in special education (Tese de doutorado não publicada). Ohio University, Estados Unidos da América.

Mcalinden, A. M. (2014). Deconstructing victim and offender identities in discourses on child sexual abuse. British Journal of Criminology, 54(2), 180-198.

Miller, L. C. (1995). Kinetic family and human figure drawing of child and adolescents sexual offenders (Tese de doutorado não publicada). Andrew University, Michigan, Estados Unidos da América.

Morrell, L. M., \& Burton, D. L. (2014). An exploration of psychopathology in self-reported measures among juvenile sex offenders. International Journal of Offender Therapy and Comparative Criminology, 58(5), 550-566.

Organização Mundial de Saúde, [OMS]. (2002). Relatório mundial sobre a violência e saúde. Recuperado de http://www.opas.org.br/cedoc/hpp/ m103/0329.pdf

Olver, M. E., \& Barlow, A. A. (2010). Public attitudes towards sex offenders and their relationship to personality traits and demographic characteristics. Behavioral Sciences \& the Law, 28(6), 832-849.

Pasqualini-Casado, L., Vagostello, L., Villemor-Amaral, A. E., \& Nascimento, R. G. (2008). Característica de personalidade de pais incestuosos por meio do Rorschach, conforme o sistema compreensivo. Psicologia: Reflexão e Crítica, 21(2), 293-301. doi: 10.1590/ S0102-79722008000200015

Passetti, E. (1999). Violentados: crianças, adolescentes e justiça. São Paulo, SP: Imaginário. 
Pechorro, P. S., Poiares, C., \& Vieira, R.X. (2008). Caracterização psicológica de uma amostra forense de abusadores sexuais. Análise Psicológica, 4(26), 615-623. Recuperado de http://www.scielo.gpeari.mctes.pt/scielo.php?script=sci_arttext\&pid=S0870-82312008000400007\&ln $\mathrm{g}=\mathrm{pt} \& \mathrm{t} \operatorname{lng}=\mathrm{pt}$

Perrot, M., Bénoy, H., Chahraoui, K., \& Juif, C. (2014). Étude des tendances dysfonctionnelles de la personnalité chez des auteurs d'infractions sexuelles. L'encéphale, 40(5), 366-372.

Pfeiffer, L., \& Salvagni, E. P. (2005). Visão atual do abuso sexual na infância e adolescência. Jornal de Pediatria, 81(5), 197-204. doi: 10.1590/ S0021-75572005000700010

Pinto Júnior, A. A. (2005). Violência sexual doméstica contra meninos: um estudo fenomenológico. São Paulo, SP: Vetor.

Retondo, M. F. N. G. (2000). Manual prático de avaliação do HTP (Casa-Árvore-Pessoa) e família. São Paulo, SP: Casa do Psicólogo.

Riveira, A. A., Ramírez, M. C., Montoya, D. O., \& Queiroz, G. (2013). Caracterización sociodemográfica, del desarrollo psicosexual y del delito en hombres condenados por delitos sexuales recluidos en el centro penitenciario de Manizales. Revista Colombiana de Psiquiatría, 42(1), 51-62. Recuperado de http://www.scielo.org.co/scielo.php? script=sci_arttext\&pid=S0034-74502013000100005\&lang=pt

Scortegagna, S. A., \& Amparo, D. M. (2013). Avaliação psicológica de ofensores sexuais com o método de Rorschach. Avaliação Psicológica, 12(3), 411-419. Recuperado de http://pepsic.bvsalud.org/scielo.php?script=sci_arttext\&pid=S1677-04712013000300016

Silva, M. A. S., Vecina, T. C. C., \& Equipe do centro de referência às vítimas de violência [CNRVV]. (2002). Mapeando a violência contra crianças e adolescentes. Em D. C. A. Ferrari \& T. C. C. Vecina (Eds.). O fim do silêncio na violência familiar: teoria e prática (pp. 277-297). São Paulo, SP: Ágora.

Willians, L. M., \& Finhelhor, D. (1990). The characteristic of incestuous fathers: A review of recent studies. Em W. L. Marshall, D. R. Laws \& H. E. Barbaree (Eds.) Handbook of sexual assault: Issues, theories, and treatment of sex offenders (pp. 231- 255). New York: Plenum Press.

Young, M. H., Justice, J. V., \& Edberg, P. (2010). Sexual offenders in prison psychiatric treatment. International Journal of Offender Therapy and Comparative Criminology, 54(1), 92-112.

Zgoba, K., \& Levenson, J. (2012). Failure to register as predictor of sex offense recidivism. Sexual Abuse: A Journal of Research and Treatment, 24(2), 328-349.

\section{Sobre as autoras}

Juliane Magda Casarin é graduada em psicologia pela Universidade Federal de Mato Grosso, possui mestrado em ciências humanas e sociais, menção psicanálise, pela Université Paris VIII e atualmente é doutoranda em psicanálise pela Université Vincennes - Saint-Dennis (Paris VIII).

Elizabeth Hertel Lenhardt Botelho é graduada em psicologia pela Universidade de Cuiabá e possui mestrado em saúde coletiva pelo Instituto de Saúde Coletiva (ISC) da Universidade Federal de Mato Grosso. Atualmente é professora do curso de Psicologia no Centro Universitário de Várzea-Grande - MT.

Rosangela Kátia Sanches Mazzorana Ribeiro é graduada em psicologia pela Universidade de Cuiabá, possui mestrado em psicologia social e da personalidade pela Pontifícia Universidade Católica do Rio Grande do Sul e doutorado em ciências pelo Programa de Pós-Graduação em Psiquiatria e Psicologia Médica da Universidade Federal de São Paulo. É professora adjunta do Departamento de Psicologia da Universidade Federal de Mato Grosso. 